\title{
Precipitation estimation by a multi-threshold method using cloud optical and microphysical properties from MSG / SEVIRI data
}

\author{
Mourad Lazri ${ }^{1,{ }^{*}, \text { KarimLabadi }^{2}, \text { Jean Michel Brucker }}{ }^{2}$ and Soltane Ameur ${ }^{1}$ \\ ${ }^{1}$ Laboratoire LAMPA, Université Mouloud MAMMERI, Tizi-Ouzou (Algérie) \\ ${ }^{2}$ ECAM-EPMI/QUARTZ-Lab (France)
}

\begin{abstract}
The aim of this paper is the estimation of precipitation in northern Algeria using satellite data. To do this, a multi-threshold method based on the exploitation of the clouds optical and microphysical properties is developed. Depending on the availability of the MSG / SEVIRI (Meteosat Second Generation/Spinning Enhanced Visible and Infrared Imaging) satellite channels, the database is divided into daytime data and nighttime data. In the learning phase, daytime and nighttime two-dimensional thresholds are determined from comparisons between the MSG / SEVIRI satellite data of rainy season 2010/2011 and the corresponding data from the Sétif meteorological radar. Using linear regression, an empirical relationship between the SEVIRI spectral data and the precipitation intensities from the radar is determined.To estimate rainfall, the determined empirical relationship is ap plied to the validation dataset collected during rainy season 2011/2012. To evaluate the method, a comparison of the estimation results with reference radar data is performed. The results show that these estimations are in good correlation with those measured by radar.
\end{abstract}

\section{Introduction}

Due to its importance to human civilization, drinking water has become a major challenge for the world's population because of the inequitable distribution of this water between different regions of the globe. To this end, the study of water resources is one of the major scientific priorities.

These last years, drinking water resources are starting to become scarce and the use of water is constantly growing. Faced with this growing use, the implementation of a reasonable and rational management plan for these resources is urgent. A considerable part of these resources comes from precipitation whose spatiotemporal distribution is highly variable. Knowledge of rainfall fields in time and space therefore contributes to better management of these water resources.

Algeria is one of the countries most affected by this water deficit. Indeed, in this region, the drinking water that is exploited comes mainly from rainfall, which is mainly concentrated in the north of the country. The north of Algeria is characterized by a humid and cold climate, and at the same time hot and dry [1].

The measurement of rainfall amounts can be carried out by rain gauges or by remote sensing means such as radar and meteorological satellites. The rain gauges measure the precipitations fallen locally with a great precision. However, to cover large areas, the establishment of a network of rain gauges is difficult to achieve, if not impossible especially for areas difficult to access. The use of radars for the direct measurement of rainfall intensities has become widespread in order to remedy the point measurements of rain gauges. Despite this success, radar coverage is still limited and cannot cover large areas. As a result, the use of optical instruments on board meteorological satellites has become essential. The satellite has a wider field of observation. However, these satellites do not provide direct measurements of precipitation intensities.

Developed studies have exploited measurements in infrared channels from satellite, which connects the height of the clouds top height and cloud top temperature to the rain rate [2]. These methods are adapted to convective systems [3]. Stratiform precipitation is not identifiable in the infrared because is relatively warm at the top and generate low to moderate rainfall intensities. To address this issue, in the case of mixed situations, precipitation estimation techniques from the clouds optical and microphysical properties are used [4] to [6]. The new generation of satellites gives rich information about these properties. This has made it possible to better relate the cloud water path to rain rates, significantly improving the classification and precipitation estimation [4].

As part of this work, we will present a multithreshold technique for precipitation estimation using the correspondences betweenMSG multi-spectral data and the Radar data. Because of the complexity of the Mediterranean climate, information about theclouds optical and microphysical properties is used here to account for both convective and stratiform systems. This article is structured as follows: in Section 2, we describe the study area and data used. Section 3 contains the methodology of developed scheme. In section 4 , the

\footnotetext{
$\overline{\text { *Corresponding author: m_lazri@yahoo.fr }}$
} 
results of estimation are presented. Finally, in section 5, we closed this article with summary and conclusions.

\section{Presentation of the study area and data}

\subsection{Study region}

The study area of $800 * 500 \mathrm{~km}^{2}$ is situated at North of Algeria. We have chosen the part which is covered by the Sétif Radar observations (figure 1). The geographic coordinates are $34^{\circ} \mathrm{N}$ to $38^{\circ} \mathrm{N}$ for latitude and $2^{\circ} \mathrm{W}$ at $9^{\circ} \mathrm{E}$ for longitude.

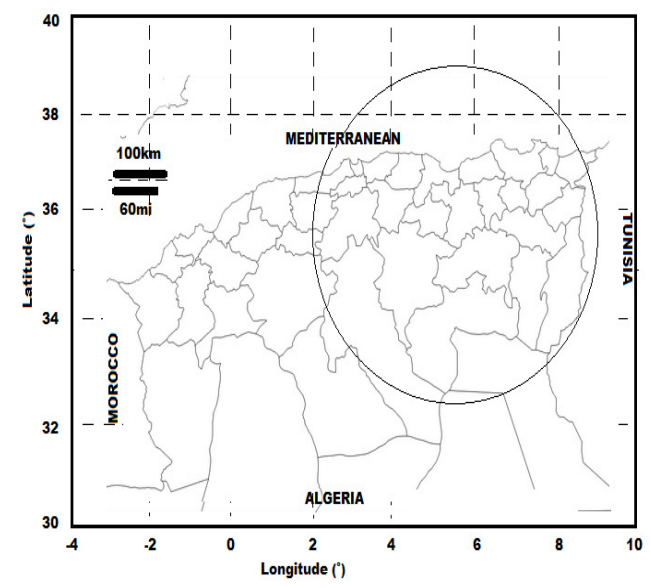

Fig. 1.Northern Algeria:Study area indicated by the circle.

\subsection{Data used}

This study exploits the data pairs of the MSG/SEVIRI multispectral radiances and the Sétif radar observations. Radar data is used for calibration and validation of the method. The radar provides direct and instantaneous measurements of precipitation intens ities, hence the choice of this type of data.

Two rainy seasons are considered in this study; data collected during November 2010 to February 2011 is used for learning the developed technique. It includes 1463 scenes of daytime and nighttime precipitation. The dataset from November 2011 to February 2012 is used for the evaluation and validation of the developed technique. It includes 1120 scenes of daytime and nighttime rainfall collected during the indicated period. To properly exploit the spectral channels of SEVIRI, the nighttime data and daytime data are used separately.

\subsubsection{Radar data}

The radar managed by National Office of Meteorology is placed at $36^{\circ} 11^{\prime} \mathrm{N}, 5^{\circ} 25^{\prime} \mathrm{E}$ and at an altitude of 1700 m.the temporal resolution and spatial resolution are respectively $15 \mathrm{~min}$ and $1 \mathrm{~km}$. A radar imageis constituted of $512 \times 512$ pixels collected in PPI (Plane Position Indicator). The number of classes for this Radar is 16 classes corresponding to different intensities of reflectivity $[04,12,18,22,26,30,34,38,42,46,50$, $54,58,62,66,70(\mathrm{dBZ})]$. The Radar reflectivity $(\mathrm{Z})$ expressed in $\left(\left(\mathrm{mm}^{6} \mathrm{~m}^{-3}\right)\right.$ can be given in dBZ.

\subsubsection{Satellite data}

This data obtained from the Spinning Enhanced Visible and Infrared Imager (SEVIRI) instrument, it is a radiometer-imager aboard the MSG (Meteosat Second Generation) satellite. The SEVIRI radiometer provides 12 images at wavelengths between 3.8 and $14 \mu \mathrm{m}$. The temporal resolution is 15 minutes and the spatial resolution is $3 * 3 \mathrm{~km}^{2}$ at the point below the satellite in all channels with the exception of the HRV channel which has a resolution of $1 * 1 \mathrm{~km}^{2}$. In the case of northern Algeria, the spatial resolution is $4 * 5 \mathrm{~km}^{2}$ due to its geographical position and the spherical shape of the Earth.

For our study, the selected satellite channels are: VIS0.6, NIR1.6, IR3.9, WV7.3 and IR10. The combination of its spectral characteristics makes it possible to provide information about clouds microphysical and optical properties that are decisive for the quantification of precipitation intensities.

In this context, the Cloud Water Path (CWP) which depends both on the size of the water and/or ice droplets $r_{e}$ and the optical thickness $\tau$ of the clouds is used. Indeed, a cloud of important optical thickness with large droplets gives significant precipitation. The relationship is given by equation 1 [4]-[7]:

$$
C W P=\frac{2}{3} \rho \tau r_{e}
$$

$\rho$ : represents the density of the water/ice in the clouds in $\left(g / m^{3}\right)$.

Several approaches based on "Look-Up-Table (LUT)" for retrieving optical thickness and effective particle radius of clouds from a radiative transfer model [8]. The results are simultaneously comparis on between satellite observed reflectances with LUT of simulated reflectances for given particle sizes and optical thicknesses. For this reason, we used CWP which is implicitly derived from the MSG/SEVIRI to estimate the precipitation.

A set of combinations obtained from the different spectral channels are selected:

The parameter $\Delta T_{I R 3.9-I R 10.8}$ gives information on the effective radius of particles and the optical thickness of clouds [9]-[4]. In the IR3.9 channel, scattering is significant for particles with smaller radius, reducing cloud emissivity. Whereas the larger particles have a higher emission. The $\Delta T_{I R 3.9-I R 10.8}$ reaches the highest values for optically thin clouds of small/large particles. Medium to high $\Delta T_{I R 3.9-I R 10.8}$ values are obtained for high optical thickness with a large particles. These values of $\Delta T_{I R 3.9-I R 10.8}$ are lower for clouds with a thin optical thickness. Small $\Delta T_{I R 3.9-I R 10.8}$ are obtained for small particles with thick clouds. 
The parameter $\Delta T_{I R 3.9-W V 7.3}$ as for the $\Delta T_{I R 3.9-I R 10.8}$ provides information on the effective radius of particles and the optical thickness of clouds [10].

The combination of $\Delta T_{I R 3.9-I R 10.8}$ and $\Delta T_{I R 3.9-W V 7.3}$ characterizes the water capacity of clouds (CWP) (Fig. 2). As a result, cloudy areas with a high CWP value correspond to higher precipitation intensities. Cloudy areas with a low CWP value result in low rainfall intensities. These two parameters, namely $\Delta T_{I R 3.9-I R 10.8}$ and $\Delta T_{I R 3.9-W V 7.3}$ are used during the nighttime. Based on parameter thresholds, we determined several levels of CWP (fig. 2).

The channels VIS0.6 and NIR1.6 are used to obtain information about the effective radius and the optical thickness of the clouds respectively [5][4]. High reflectance values of VIS0.6 show a high optical cloud thickness and low reflectance values of NIR1.6 correspond to large particles in the cloud. It should be noted that these two channels are available during the day. The combination of the two channels $\left(R_{V I S 0.6}\right.$ and $R_{\text {NIR1.6 }}$ ) characterizes the CWP (Fig. 3). To determine the levels of CWP, thresholds are used.
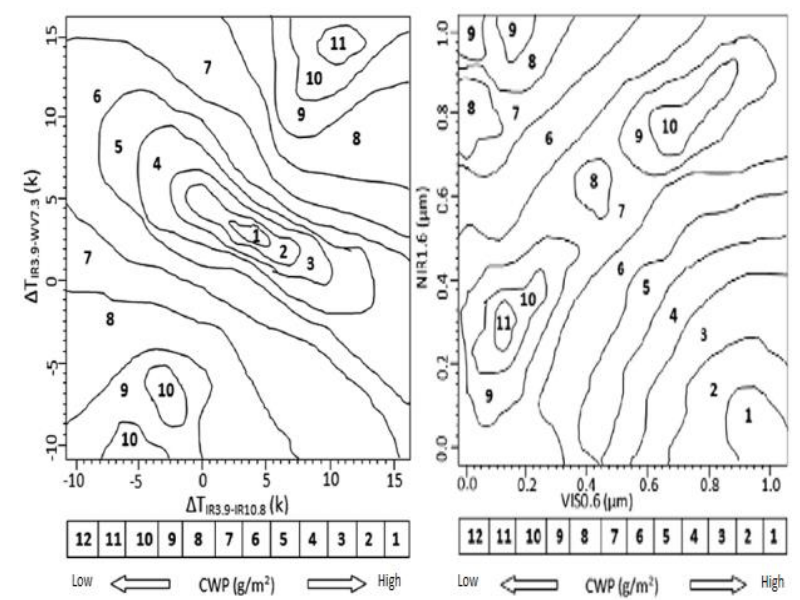

Fig.2.Cloud water path(CWP) versus $\Delta T_{I R 3.9-I R 10.8}$ and $\Delta T_{I R 3.9-W V 7.3}$ (left), Cloud water path (CWP) versus VIS0.6 and NIR1.6 (right) [11].

The following Table illustrates the multi-spectral parameters used in this work.

Table 1.Multi-spectral parameters used.

\begin{tabular}{|c|c|c|}
\hline & $\begin{array}{c}\text { Spectral } \\
\text { parameters }\end{array}$ & \multicolumn{1}{c|}{ Definition } \\
\hline \multirow{2}{*}{$\begin{array}{c}\text { Night } \\
\text { time }\end{array}$} & $\Delta T_{I R 3.9-I R 10.8}$ & $\begin{array}{l}\text { brightness temperature difference } \\
\text { between } I R 3.9 \text { and } I R 10.8\end{array}$ \\
\cline { 2 - 3 } & $\Delta T_{I R 3.9-W V 7.3}$ & $\begin{array}{l}\text { brightness temperature difference } \\
\text { between } I R 3.9 \text { and } W V 7.3\end{array}$ \\
\hline \multirow{2}{*}{$\begin{array}{c}\text { Day } \\
\text { time }\end{array}$} & $R_{\text {NIR1.6 }}$ & Reflectance of the canalNIR 1.6 \\
\cline { 2 - 3 } & $R_{V I S 0.6}$ & Reflectance of the canal $V I S 0.6$ \\
\hline
\end{tabular}

\subsubsection{Spatio-temporal correspondence between radar and satellite}

The original spatial resolution of Sétifradar data $(1 \mathrm{x}$ $1 \mathrm{~km}^{2}$ ) was re-projected and resampled to spatial resolution $4 \times 5 \mathrm{~km} 2$, which corresponds to the resolution of the data of SEVIRI in the study area (northern Algeria). Due to the small area of overlap observed by the satellite and Radar, the spatial resolution is fixed at $4 \times 5 \mathrm{~km}^{2}$.

The comparison of the two images may be hampereddue to parallax offsets and co-location errors. This parallax offsets occurs because SEVIRI observes the study area at an oblique angle. Thus, to find the maximum correlation between the SEVIRI images and radar images, a radar pixel has been replaced by the average of the $5 \times 5$ neighborhood pixels for the highlevel clouds, and the average of the $3 \times 3$ pixels for the low level clouds.

\section{Methodology}

In order to estimate precipitation using satellite data, we used a linear regression established between precipitation intensities and the CWP parameter (Fig.5). Due to the inadequacy of the IR3.9 channel during the day and to the unavailability of VIS0.6 and NIR1.6 at nighttime and, two models were developed, a daytime model and a nighttime model.

The method is based on the use a multi-threshold of spectral parameters to identify the CWP levels. The description of the multi-threshold method (MULTh) is presented in Fig. 3.

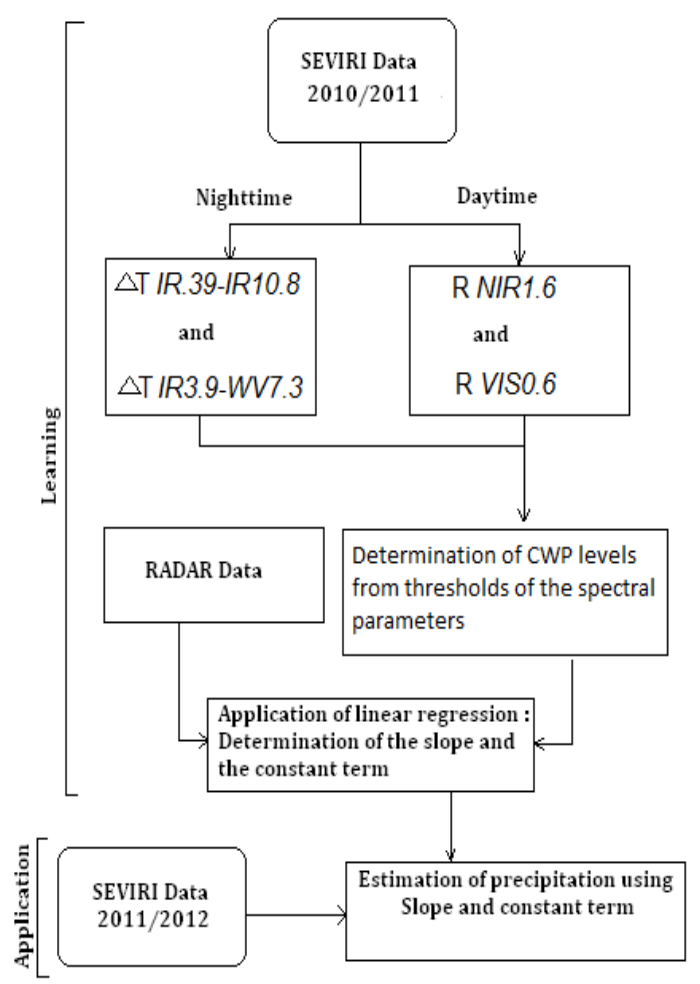

Fig.3. Flowchart of the developed method. 
During the nighttime, we traced the variations of the parameters $\Delta T_{I R 3.9-I R 10.8}$ and $\Delta T_{I R 3.9-W V 7.3}$ according to the radar reflectivities (fig. 4). Similarly, the RVIS0.6 and RNIR1.6 parameter changes as a function of radar reflectivity are plotted in Fig. 4.
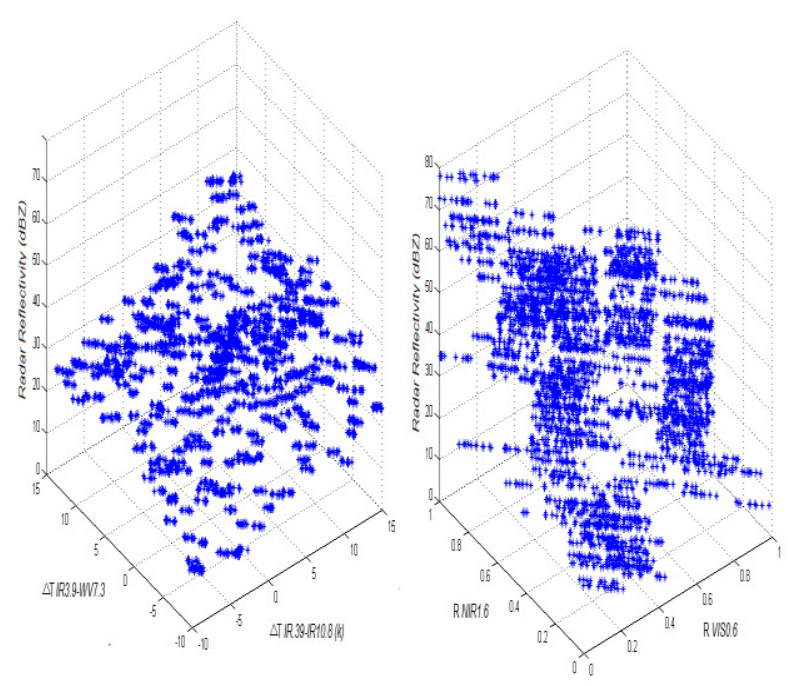

Fig. 4. Radar reflectivities versus $\Delta T_{I R 3.9-I R 10.8}$ and $\Delta T_{I R 3.9-W V 7.3}$ (left), Radar reflectivity versus RVIS0.6 et RNIR1.6 (right).

The fig. 4 shows that there is a relationship between the spectral parameters and the radar reflictivities. To relate the CWP to precipitation intensities, we have represented CWP levels as a function of radar reflectivities (Fig. 5).

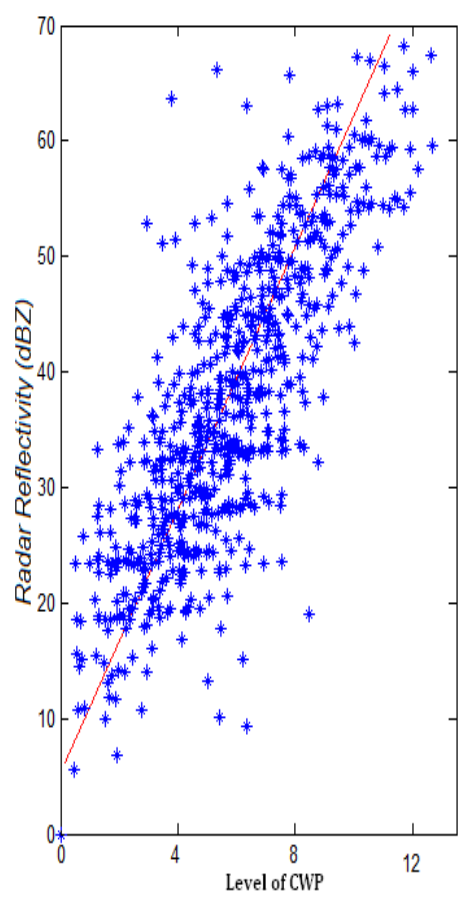

Fig.5. Radar reflectivities versus CWP.

Using linear regression, we were able to establish a mathematical relationship. The relationship between CWP and radar reflectivity is given by equation 2 :
$R(d B Z)=S \cdot C W P+c$

Where $\mathrm{R}$ is the radar reflectivity, $\mathrm{S}$ is the slope and is the constant term. In our case, we found $\mathrm{S}$ and c equal to 5.2 and 6.4 respectively.

\section{Results of rainfall estimation}

In this section, we calculated cumulative precipitation on monthly scales during the 2011/2012 rain period. To do this, we used the CWP levels obtained from the SEVIRI data and the two parameters $\mathrm{S}$ and $\mathrm{c}$ determined in the linear regression. Using equation 2 , these estimates at the study area and at monthly time intervals (November, December, January and February) were calculated. The results of these estimates and the radar measurements are shown in Fig. 6.

To show the performance of the method, we calculated a set of evaluation parameters equations (3) to (6).

- The correlation coefficient

$r=\frac{\sum_{i=1}^{N}\left(E_{i}-\overline{E_{l}}\right)\left(V_{i}-\bar{V}_{i}\right)}{\sqrt{\sum_{i=1}^{N}\left(E_{i}-\overline{E_{l}}\right)^{2}} \sqrt{\sum_{i=1}^{N}\left(V_{i}-\bar{V}_{i}\right)^{2}}}$

- The Root Mean Square Difference

$R M S D=\sqrt{\frac{1}{N} \sum_{i=1}^{N}\left(E_{i}-V_{i}\right)^{2}}$

- The bias

Bias $=\frac{1}{N} \sum_{i=1}^{N}\left(E_{i}-V_{i}\right)$

- The Mean Absolute Difference

$M A D=\frac{1}{N} \sum_{i=1}^{N}\left|E_{i}-V_{i}\right|$

Where:

$E_{i}$ : The estimated value.

$V_{i}$ : The value of the radar validation data.

$\bar{E}_{i}$ : The average value of the estimates.

$\bar{V}_{i}$ : The average value of the radar validation data.

The evaluation parameters obtained are shown in the Table 2. The MULThmethod was also compared to the WkNN technique (weighted $\mathrm{k}$ nearest neighbor) implemented by Bensafi et al, (2019) [12] using the same database. The results of comparison are indicated in table 2 .

The Fig. 6 shows that the fluctuations are larger in December and January than in November and February. This is corroborated by the correlation coefficients given in Table 2. The correlation coefficients vary between 0.86 and 0.89 . The month of January has the highest correlation coefficient $(r=0.89)$, this is due to the presence of significant precipitation, especially those of stratiform type. 
The values of the evaluation parameters (RMSD, Bias and MAD) show that the estimates obtained are close to the actual measurements. The best estimates are obtained for the months of December and January compared to the months of November and February. The precipitation scenes observed during these two months are dominated by stratiform precipitation. While convective rainfall is most observed during the months of November and February. The elaborate technique shows interesting performances for stratiform precipitation.

Table 2 shows the evaluation parameters for precipitation estimation obtained by the application of the WkNN technique and the application of the MULTh technique. According to the comparis on results, the MULTh techniqueshows superior performances compared to the $\mathrm{WkNN}$ techniques.

The application of the MULTh technique to the SEVIRI data has improved the results of the precipitation estimation by taking into account the different types of cloud. The use of the CWP has contributed to better estimate rainfall. The MULTh technique estimates better the stratiform precipitations. This remarkable performance for stratiform precipitation is due to the dominance of water content in this type of cloud contrary to the ice content
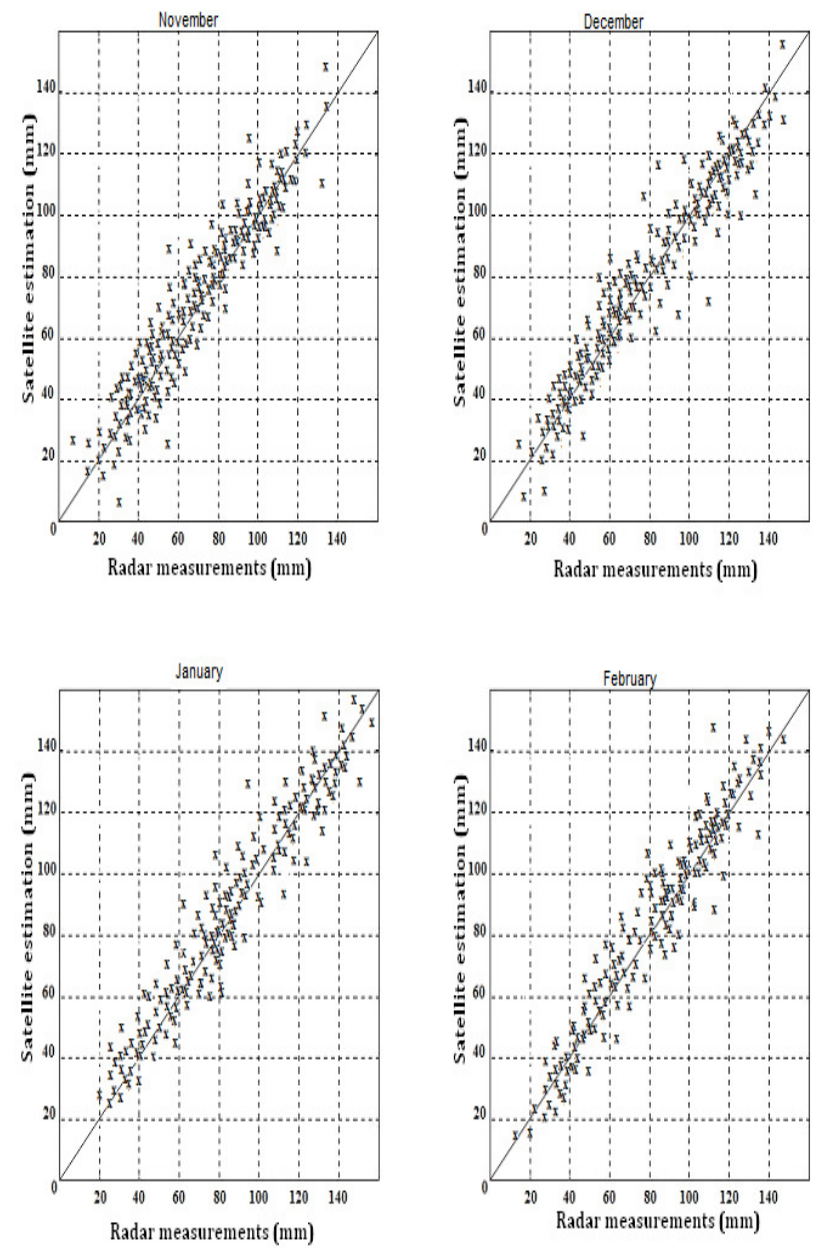

Fig.6. Satellite estimation versus radar measurements
Table 2.Parameters of evaluation of the cumulative precipitation estimated by the techniques WkNN and MULTh.

\begin{tabular}{|c|c|c|c|c|c|c|c|c|}
\hline & \multicolumn{3}{|c|}{ WNNN Technique } & \multicolumn{4}{c|}{ MULThTechnique } \\
\cline { 2 - 8 } & r & $\begin{array}{c}\text { RMSE } \\
(\mathbf{m m})\end{array}$ & $\begin{array}{c}\text { Bias } \\
(\mathbf{m m})\end{array}$ & $\begin{array}{c}\text { MAE } \\
(\mathbf{m m})\end{array}$ & $\mathbf{r}$ & $\begin{array}{c}\text { RMSE } \\
(\mathbf{m m})\end{array}$ & $\begin{array}{c}\text { Bias } \\
(\mathbf{m m})\end{array}$ & $\begin{array}{c}\text { MAE } \\
(\mathbf{m m})\end{array}$ \\
\hline November & 0.85 & 15.45 & -4.52 & 12.58 & 0.86 & 14.7 & -3.6 & 10.2 \\
\hline December & 0.87 & 12.58 & 2.85 & 8.25 & 0.88 & 10.5 & 2.5 & 7.6 \\
\hline January & 0.88 & 11.62 & 2.94 & 7.29 & 0.89 & 09.1 & 2.4 & 7.3 \\
\hline February & 0.87 & 17.23 & -3.74 & 10.58 & 0.87 & 16.6 & -5.7 & 11.3 \\
\hline
\end{tabular}

\section{Conclusion}

The aim of this work is to develop a precipitation estimation technique applied to the northern Algeria using MSG satellite data. In this context, the technique aims to improve rainfall estimates, on the one hand, and extend these estimates to areas not covered by meteorological radar and / or rain gauges. The developed scheme is based on the exploitation of the optical and microphysical properties of clouds. The advantage of such a technique is that it can be applied both for convective systems and stratiform systems. The MULTh method compares CWP levels to precipitation intensities. A linear relationship has been established using linear regression.

Using this method, estimates of totals precipitation are determined. These estimates are compared to radar measurements. The results indicate a good correlation between the satellite estimates and the Radar measurements. The results also show that best estimates are obtained for stratiform precipitation. In this type of precipitation, precipitation intensities are proportional to CWP levels.

The results of the MULTh technique are also compared to the results obtained by applying the $\mathrm{WkNN}$ technique. The results showed a clear improvement for precipitation estimation using the MULTh method. However, in the case of convective precipitation estimates, the developed method showed a slight underestimation due to the presence of ice clouds. The MULTh method seems to be more interesting for the extratropical regions where advective-stratiform precipitation is dominant.

The perspective of this work is that it would be interesting to integrate the Cloud Ice Path to consider clouds with ice in its top, such as cumulonimbus.

\section{References}

1. Trigo, R., Xoplaki, E., Zorita, E., Luterbacher, J., Krichak, S.O., Alpert, P., Jacobeit, J., Sàenz, J., Fernàndez, J., Gonzàlez-Rouco, F., Garcia- Herrera, R., Rodo, X., Brunetti, M., Nanni, T., Maugeri, M., Turkex, M., Gimeno, 18 L., Ribera, P., Brunet, M., 
Trigo, I.F., Crepon, M., Mariotti, A., Chapter 3 Relations between variability in the Mediterranean region and mid-latitude variability. In: Developments in Earth and Environmental Sciences, vol. 4. Elsevier, pp. 179-226 (2006).

2. Hong, Y., Hsu, K.-L., Sorooshian, S., Gao, X., Precipitation estimation from remotely sensed imagery using an artificial neural network cloud classification system. J. Appl. Meteorol. 43, 18341853 (2004).

3. Ebert, E.E., Janowiak, J.E., Kidd, C., Comparis on of near-real-time precipitation estimates from satellite observations and numerical models. Bull. Am. Meteorol. Soc. 88, 47-64 (2007)

4. Thies, B., Nauss, T., \& Bendix, J., Precipitation process and rainfall intensity differentiation using Meteosat Second Generation SEVIRI data. Journal of Geophysical Research, 113, 19 (2008).

5. Lazri, M., Ameur, S.,.A satellite rainfall retrieval technique over northern Algeria based on the probability of rainfall intensities classification from MSG-SEVIRI. J. Atmos. Sol. Terr. Phys. 147, 106120 (2016).

6. Levizzani, V., Satellite rainfall estimations: new perspectives for meteorology and climate from the EURAINSAT project, Ann. Geophys., 46, 363-372, http://www.ann-geophys.net/46/363/2003/ (2003).

7. Nauss, T., Kokhanovsky, A.A., Assignment of rainfall confidence values using multispectral satellite data at mid-latitudes: first results. Adv. Geosci. 10, 99-102 (2007).

8. Roebeling, R.A., Holleman, I., SEVIRI rainfall retrieval and validation using weather radar observations. J. Geophys. Res. 114 (2009).

9. Lazri, M., Ameur, S., Mohia, Y., Instantaneous rainfall estimation using neural network from multispectral observations of SEVIRI radiometer and its application in estimation of daily and monthly rainfall. Adv. Space Res. 53, 138-155 (2014).

10. Schmetz, J., Pili, P., Tjemkes, S., Just, D., Kerkmann, J., Rota, S., Ratier, A., 2002. An introduction to Meteosat Second Generation (MSG). Bull. Am. Meteorol. Soc. 83, 977-992 (2002).

11. Lazri, M., Ameur, S., Brucker, J.M., Testud, J., Hamadache, B., Hameg, S., Ouallouche, F., Mohia, Y., Identification of raining clouds using a method based on optical and microphysical cloud properties from Meteosat second generation daytime and nighttime data. Appl. Water Sci. 3, 1-11 (2013).

12. Bensafi N., Lazri M., Ameur S., Novel WkNNbased technique to improve instantaneous rainfall estimation over the north of Algeria using the multispectral MSG SEVIRI imagery, Journal of Atmospheric and Solar-Terrestrial Physics, doi.org/10.1016/j.jastp.2018.12.004 (2019). 